\title{
A FONTE DA FALA
}

Josely Vianna Baptista

Josely Vianna Baptista é autora de Ar e Corpografia (lluminuras, 1991/92), A Concha das Mil Coisas Maravilhosas do Velho Caramujo (Mirabilia, 2001 ilust. G. Zamoner -VI Prémio Internacional del Libro llustrado Infantil y Juvenil do Governo do México), On the shining screen of the eyelids(Manifest, 2003, trad. Chris Daniels), Florid pores (in 1913. A journal of forms. Roanoke, 2006, trad. Daniels e Alfarano), Sol sobre nuvens (Perspectiva, 2007, apres. Augusto de Campos), Roça Barroca (Cosac Naify), entre outros. Em 2009 teve seu trabalho representado em The Oxford Book of Latin American Poetry (NY, Oxford University Press Org. E Livon-Grosman e C Vicuña). Criou a colecão Cadernos da Ameríndia. Tradutora de literatura hispanoamericana, trouxe ao português obras de Roa Bastos, Lezma hispanoaArguedas, Cortázar, Cabrera Infante e Borges, entre outros. Desde 1992 desenvive com Francisco Faria um trabalho que associa poesi 1992 visuais. Seu trabalho mais recente é o site multimídia Na tela rútila das pálpebras feito em colaborac̃a com diversos poetas e artistas (apoio Rumos Itaú Cultural). Mora na llha de Santa Catarina. 
Neste canto, o deus supremo vai desdobrando de si o fulgor do fogo e a neblina que dá vida, a fonte do amor e do som sagrado. Faz a fonte da fala aflorar de si e fluir por seu corpo, tornando-a sagrada, palavra-alma de origem divina. Desdobra de si os homens e as mulheres que iriam refletir sua divindade, Namandu de Grande Coração, Karaí, Jakaira e Tupã, pais e mães verdadeiros da palavra inspirada que insuflará a alma em seus numerosos filhos futuros.

$$
\text { *** }
$$

\section{A FONTE DA FALA}

Ñamandu, nosso Pai verdadeiro, o primeiro,

de uma pequena parte de seu ser-de-céu,

do saber contido em seu ser-de-céu,

e sob o sol de seu lume criador,

alastrou o fulgor do fogo e a neblina que dá vida.

2

Incorporando-se

com o saber contido em seu ser-de-céu,

e sob o sol de seu lume criador,

iluminou-se a fonte da fala.

Com o saber contido em seu ser-de-céu,

e sob o sol de seu lume criador, nosso Pai iluminou-se a fonte da fala

e fez com que fluísse por seu ser, divinizando-a.

Antes de a Terra existir,

no caos obscuro do começo,

tudo oculto em sombras,

Namandu, Pai verdadeiro, o primeiro,

aflorou-se a fonte da fala e fez com que fluísse por seu ser, divinizando-a.

A fonte da futura palavra tendo aflorado,

com o saber contido em seu ser-de-céu,

e sob o sol de seu lume criador,

de si foi aflorando a fonte do amor.

Tendo aflorado a fonte da fala,

tendo aflorado um pouco de amor

com o saber contido em seu ser-de-céu,

e sob o sol de seu lume criador

o princípio de um som sagrado ele, a sós, criou.

Antes de a Terra existir,

no caos obscuro do começo,

tudo oculto em sombras,

o princípio de um som sagrado ele, a sós, criou. 
Tendo aflorado, a sós, a fonte da futura fala,

e desdobrado, a sós, um pouco de amor

tendo criado, a sós, um breve som sagrado,

ele refletiu longamente

sobre com quem compartilhar a fonte da fala

sobre com quem compartilhar o amor,

com quem partilhar as fieiras de palavras do som sagrado.

Depois de muito meditar,

com o saber contido em seu ser-de-céu,

e sob o sol de seu lume criador

desdobrou-se em quem refletiria

seu ser-de-céu.

Depois de refletir,

com o saber contido em seu ser-de-céu,

e sob o sol de seu lume criador,

criou o Namandu de Grande Coração.

Criou-o juntamente com o sol de seu lume criador.

Antes de a Terra existir

no caos obscuro do começo,

criou o Ñamandu de Grande Coração.

Para que fosse o pai de seus muitos filhos vindouros,

o verdadeiro pai das almas dos numerosos filhos vindouros,

ele criou o Ñamandu valoroso.
Depois disso,

com o saber contido em ser-de-céu,

e sob o sol de seu lume criador,

tornou lúcidos da própria divindade

o verdadeiro pai dos futuros Karaí,

o verdadeiro pai dos futuros Jakaira

o verdadeiro pai dos futuros Tupã.

Depois disso,

o verdadeiro Pai Ñamandu,

para refletir seu coração,

fez que se soubesse divina

a futura Mãe verdadeira dos Namandu;

o verdadeiro Pai Karaí,

para refletir seu coração,

fez que se soubesse divina

a futura Mãe verdadeira dos Karaí.

Também o verdadeiro Pai Jakaira,

para refletir seu coração,

fez que se soubesse divina

a futura Mãe verdadeira dos Jakaira.

E o verdadeiro Pai Tupã,

para refletir seu coração,

fez que se soubesse divina

a futura Mãe verdadeira dos Tupã. 
Por terem recebido o lume

divino do próprio Pai primeiro;

por terem recebido a fonte da fala;

por terem recebido a fonte do amor

e as fieiras de palavras do som sagrado;

por estarem unidos à origem do saber criador,

também os chamamos de

inspirados pais verdadeiros das palavras-almas;

inspiradas mães verdadeiras das palavras-almas.

\section{AYVU RAPYTA}

Namandu Ru Ete tenondegua

oyvára petềgui,

oyvárapy mba'ekuaágui,

okuaararávyma

tataendy, tatachina ogueromoñemoña.

Oãmyvyma,

oyvárapy mba’ekuaágui,

okuaararávyma

ayvu rapytarã i oikuaa ojeupe.

Oyvárapy mba'ekuaágui,

okuaararávyma, ayvu rapyta oguerojera,

ogueroyvára Nande Ru.

Yvy oiko'ë̈re,

pytû yma mbytére,

mba'e jekuaa'ë̈re,

ayvu rapytarã i oguerojera,

ogueroyvára Namandu Ru Ete tenondegua.

Ayvu rapytarã i oikuaámavy ojeupe,

oyvárapy mba’ekuaágui,

okuaararávyma

mborayu rapytarã oikuaa ojeupe.

Yvy oiko'eyre,

pytû yma mbytére

mba'e jekuaa'ë̈re,

okuaararávyma

mborayu rapytarã i oikuaa ojeupe.

Ayvu rapytarã i oguerojera $i$ mavy

mborayu petề i oguerojera i mavy,

oyvárapy mba'ekuaágui,

okuaararávyma

mba'e a'ã rapyta petề oguerojera.

Yvy oiko'eÿre,

pytû yma mbytére, 
mba'e jekuaa'eÿre

mba'e a'ã petề i oguerojera ojeupe.

Ayvu rapytarã i oguerojera i mavy ojeupe mborayu peteî oguerojera i mavy ojeupe mba'e a'ã petề oguerojera i mavy ojeupe,

ochareko iñomá

mavaêpepa ayvu rapyta omboja'o i anguã

mborayu petế $i$ omboja'o $i$ anguã,

mba'e a'ã ñeychyrõgui omboja'o $i$ anguã.

Ochareko iñomavy,

oyvárapy mba'ekuaágui,

okuaararávyma

oyvára irûrã i oguerojera.

Ochareko iñomavy,

oyvárapy mba'ekuaágui,

okuaararávyma

Namandu Py'a Guachu oguerojera.

Jechaka mba'ekuaa reve oguerojera.

Yvy oiko'ë̈re,

pytû yma mbytére,

Nãmandu Py'a Guachu oguerojera.

Gua'y reta ru eterã

gua'y reta ñe'êy ru eterã,
Ñamandu Py'a Guachu oguerojera.

A'e va'e rakyguégui,

oyvárapy mba'ekuaágui,

okuaararávyma,

Karaí Ru Eterã,

Jakaira Ru Eterã,

Tupã Ru Eterã

omboyvárajekuaa.

Gua'y reta ru eterã

gua'y reta ñe êy ru eterã,

omboyvára jekuaa.

A'e va'e rakyguégui

oyvárapy mba'ekuaágui,

okuaararávyma

Karaí Ru Eterã,

Jakaira Ru Eterã

Tupã Ru Eterã,

omboyvárajekuaa.

Gua'y reta ru eterã

gua'y reta ñe'êy ru eterã, omboyvára jekuaa.

A'e va'e rakykuégui,

Namandu Ru Ete 
opy’a rechéiguarã

omboyvára jekuaa

Namandu Chy Eterã i;

Karai Ru Ete,

omboyvára jekuaa

opy’a rechéiguarã

Karaí Chy Eterã i.

Jakaira Ru Ete, a'érami avei,

opy'a rechéi guarã

omboyvárajekuaa

Jakaira Chy Eterã i.

Tupã Ru Ete, a'érami avei,

opy'a rechéi guarã

omboyvárajekuaa

Tupã Chy Eterã i.

Guu tenondegua yvárapy

mba'ekuaa omboja'o riréma

ayvu rapytarã i omboja riréma;

mborayu rapyta omboja'o riréma;

mba'e a'ã ñeychyrõ omboja'o riréma;

kuaarara rapyta ogueno'ã rire,

a'ekue ipy:

$\tilde{N} e^{\prime} \hat{e} y$ Ru Ete pavêngatu,

Ne'êy Chy Ete pavêngatu,

ja'e.

\section{BREVE ELUCIDÁRIO}

(As notas lexicológicas e os comentários foram feitos a partir de vocábulos, versos ou blocos de versos (conforme a necessidade de contextualização), com aquelas se concentrando nos dois primeiros cantos, pois no último se repetem muitas palavras e conceitos já esclarecidos anteriormente. Eventualmente "disseco" um verso ou estrofe para dar um vislumbre do arcabouço da língua original, mas, para poupar o leitor de minha "oficina", tais ocorrências se limitam a uma fração mínima do trabalho percorrido para a tradução).

\section{Ayvu rapyta/A fonte da fala}

ayvu: linguagem humana; idioma, fala. apyta: base, alicerce, origem; apy: extremidade; yta: apoio. $\mathrm{O}$ fundamento da linguagem humana, a fonte da fala, é a palavra-alma originária, "aquela que Nossos Primeiros Pais repartiriam com seus numerosos filhos ao enviá-los à morada terrena para se erguerem [nascerem]", conforme relato do cacique Pablo Vera num encontro com Cadogan. Na versão do mburuvicha Kachirito, de Paso Jovái, "a fonte da fala foi criada por Nosso Primeiro Pai, que a fez parte de sua divindade, para medula da palavra-alma”. (Ayvu, 42) Aliás, foi a descoberta intrigante e instigante de que ayvu (linguagem humana), ñé êy(palavra) e $e$ (dizer) contêm o duplo conceito de "expressar ideias" e "porção divina da alma" que levou Cadogan a debruçar-se, anos a fio, no estudo da religião guarani. 


\section{okuaararávyma}

kuaarara:, significa sabedoria, poder criador (kuaa: saber; ra: radical de jera, mbojera,guerojera: criar)

Kuaarara é um dos termos sagrados mais importantes para os Guarani, que não o pronunciam diante de estranhos. Em meio ao caos obscuro do começo, o deus supremo foi iluminado pelo brilho de seu próprio coração, sendo kuaarara a fonte dessa luz que antecedeu a criação do sol: seu "sol" era o saber contido em seu "ser-de-céu".

\section{tataendy, tatachina ogueromoñemoña.}

tataendy: chamas (manifestação visível da divindade). Karaí Ru Ete é o nume protetor das chamas divinas. De tata: - ata: fogo e endy: brilho, luz.

tatachina (tatachi: fumaça; na: semelhante a): termo pertencente ao vocabulário religioso, nomeia a neblina que aparece no fim do inverno, prenunciando o viço da primavera e o calor. Ñamandu vai multiplicando o fogo fulgurante e a névoa que dá vida. Essa neblina, que para os Mbyá propicia a revitalização de todos os seres, tem seu "duplo terreno" na fumaça de tabaco que "ascende" ao ser exalada pelos sacerdotes indígenas em seus rituais, simbolizando um meio de comunicação com o deus primeiro. Jakaira Ru Ete é seu nume protetor.

\section{Oãmyvyma}

ã: estar erguido; py, mby: partícula verbal; ma: já

$>$ Incorporando-se/Tendo-se erguido,

Ou seja, tendo tomado a forma humana.

\section{mborayu rapytarã oikuaa ojeupe}

Embora literalmente mborayu signifique "amor", seu sentido neste canto é controverso. A tradução de Cadogan, "amor ao próximo”, encontra eco na acepção dada por Montoya em seuTesoro de la Lengua Guarani, qual seja, o amor de Deus por suas criaturas e vice-versa. Discordando, Pierre Clastres argumenta que os missionários adotaram tendenciosamente o termo mborayu "para exprimir a ideia cristã do amor", e que, nesse sentido, a tradução de Cadogan "não é falsa, mas imprópria” ( $A$ fala sagrada, 31). Clastres optou por uma expressão, "o que está destinado a reunir", por acreditar que o termo irradia o conceito de "solidariedade tribal".

4

\section{mba'e a'â rapyta peteî oguerojera}

mba'e a'ã: canto ou hino sagrado. 
$a^{\prime} \tilde{a}\left(h a^{\prime} \tilde{a}\right)$ : empenhar-se (em busca de força espiritual).

Cantos e rezas são um esforço em busca de alento e coragem. Os Guarani “recebem em sonhos" seus próprios cantos rituais. Tomo a liberdade de relatar aqui uma experiência ocorrida em Ocoy, quando lá estive para conversar com os índios sobre os mitos que estava traduzindo. Eu levava em mãos os originais dos cantos e um esboço da tradução. Entreguei-os a Teodoro. Ele primeiro presenteou meu filho Pedro Jerônimo com um arco e flecha de sua própria lavra, e então começou a "cantar" sua versão do primeiro canto, parando, por vezes, para relembrar alguma passagem, e consultando o manuscrito com genuíno interesse. Depois nos levou até o líder religioso da aldeia. Logo estávamos rodeados de moradores, que comentavam passagens dos cantos, discordavam aqui e ali do registro, aportavam e explicavam variantes, numa reunião memorável de revivificação do mito.

\section{mavaêpepa ayvu rapyta omboja'o $i$ anguã}

mboja'o: repartir, distribuir. Diz-se também amboja’o aran$d u$ : assimilo sabedoria dos deuses.

> sobre com quem compartilhar a fonte da fala

mba'e a'ã ñeychyrõgui omboja'o i anguã. ñeychyrõ: repetir-se, pôr-se em filas.

> sobre com quem compartilhar as séries de palavras do som sagrado.

\section{Namandu Py'a Guachu}

guachu: grande; py'a: fígado, coração; py’a guachu: lit.: de fígado grande; aqueles que têm

grande coração, os valorosos.

\section{gua'y reta ñe'êy ru eterã}

$\tilde{n} e$ êy: espírito que os deuses enviam para encarnar-se na criança que está para nascer; porção divina da alma, palavra-alma.

$>$ Da palavra-alma de seus muitos futuros filhos o verdadeiro pai

O conceito de palavra-alma é central na mitologia dos Mbyá. Vimos como se descreve a criação da linguagem pelo deus supremo, sendo, ela, portanto, de origem divina, embrião da palavra-alma que os deuses enviam à Terra para "habitar" um recém-nascido. Em El Guaraní: experiencia religiosa, Bartomeu Melià afirma que a união sexual entre um homem e uma mulher é a ocasião "para que se dê esse ato poético mediante o qual a palavra sonhada pelo pai é comunicada 
à mãe, que desse modo engravida dessa mesma palavra. O fato de ser gerado e concebido um ser humano é designado metaforicamente pelos Mbyá com a expressão:oñemboapyka "se dá assento", com clara alusão ao modo como Ñande Ru (Nosso Pai), senta-se em seu banquinho ritual, iluminando-se a si mesmo em meio às trevas. [...] Se a concepção e o nascimento de um Guarani se resume a um ato poético de encarnação da palavra, toda a vida do mesmo será recriação desse ato inicial, de diversas maneiras.” (trad. D. Diegues)

\section{Karaí Ru Eterã}

$>$ o verdadeiro pai dos futuros Karaí

Karaí é o nume protetor do fogo. Assim, surgiriam labaredas nas mãos e nos pés dos tocados pela inspiração divina. As chamas seriam a manifestação visível da divindade. Clastres estende o sentido para chama, fogo solar e calor, sugerindo que o movimento do sol "garante aos Guarani que os deuses não estão mortos”. (A fala sagrada, 39) Vale notar que para os Guarani o fim do mundo está ligado ao sol: a Terra começará a ruir pelo poente, e o sol não mais surgirá.

\section{Jakaira Ru Eterã}

$>$ o verdadeiro pai dos futuros Jakaira

Jakaira é o nume protetor da primavera e da neblina vivificante.

\section{Tupã Ru Eterã}

$>$ o verdadeiro pai dos futuros Tupã

Tupã é o nume protetor das tempestades, trovões, raios, relâmpagos, nuvens, águas. Segundo Chase-Sardi, embora houvesse muitos outros deuses na teogonia guarani a catequização colonial o "transformou em único e supremo Deus”. (Neblina vivificante, 13)

\section{Namandu Chy Eterã $i$}

Chy: mãe.

$>$ a futura Mãe verdadeira dos Ñamandu

\section{Ne'êy Ru Ete pavêngatu,}

\section{Neềy Chy Ete pavêngatu}

$>$ inspirados pais verdadeiros das palavras-almas; inspiradas mães verdadeiras das palavras-almas 
$\tilde{N} e^{\prime} \hat{e} y$ é o espírito enviado pelos deuses para que se encarne na criança prestes a nascer, diz Cadogan. Seu longo comentário sobre o papel da palavra na religião guarani, fruto de exaustivas pesquisas, é valioso para sua compreensão: "Em guarani comum ñeế significa linguagem humana, aplicando-se também ao cantar das aves, ao chirriar de algus insetos, etc. Em mbyá, aplica-se ao ruído de insetos, aves e animais; em ñe'ê porã tenonde significa "as primeiras palavras bonitas", por exemplo, as tradições e mitos "esotéricos", embora para designar estes aplique-se mais frequentemente a frase ayvu porã. Ñe'enguchu: voz forte, potente; a mudança de voz na puberdade; com a palavra ñemoñe'ê designam algumas mensagens recebidas dos deuses, especialmente as recebidas de Karaí Ru Ete. Nestes casos, a pronúncia de ñeêe é idêntica à que tem em nosso guarani. Tem, no entanto, outro significado: "porção divina da alma" ou "palavra-alma", e neste caso é pronunciada ñéeng, com o som dang final inglesa e alemã, seguida de um brevíssimo $y$ nasal. [...] Ne êêy, a palavra-alma de origem divina, não deve ser confundida com ãngue, palavra empregada no vernáculo para designar a alma de um defunto. (Ayvu, 43) 